\title{
The Quantity of Natural Surfactant Necessary to Prevent the Respiratory Distress Syndrome in Premature Lambs
}

\author{
MACHIKO IKE(;AMI."'" FORREST H. ADAMS. BERNARI) TOWERS. AND ALAN B. OSHER \\ Fetal-Maternal Research Lahoratories, Harbor-U Cl.A Medical Center. Torrance. California /M.I./. and Division of \\ Cardiologr. Department of Pediatrics. UCLA School of Medicine, Los Angeles, California. USA /H. H. A., B. T., A. \\ B. $O .1$
}

\section{Summary}

Premature lambs at 118 to 122 days of gestation were delivered by caesarean section and received before the first breath $0,19,53$ or $64 \mathrm{mg}$ natural surfactant total lipid (TL) per $\mathrm{kg}$ body weight (BW). The seven lambs receiving no surfactant died within $\mathbf{4 0 . 1}$ $\pm 7.5 \mathrm{~min}$, whereas the lambs treated with surfactant survived the 2-hr experimental period. Nineteen mg surfactant TL, per $\mathrm{kg} \mathrm{BW}$ preserved lung function; the $\mathrm{pH}$ and blood gas measurements were similar to those measured in lambs receiving $53 \mathrm{mg}$ TL per $\mathrm{kg} \mathrm{BW}$ or more surfactant. Pressure volume and surface tension characteristics were significantly improved after the administration of 19 mg of surfactant, but surface activity was still poor when compared to lambs receiving $53 \mathrm{mg}$ TL per $\mathrm{kg} \mathrm{BW}$ or more surfactant. The dose of surfactant (53 $\mathrm{mg}$ TL per $\mathrm{kg} \mathrm{BW}$ ) that resulted in good surface activity measurements in vitro was similar to other estimates of the amount of surfactant necessary to cover the alveolar space.

\section{Speculation}

Differences were observed in the quantities of surfactant needed to normalize the clinical status and the pressure-volume and surface balance characteristics of the excised lungs and lung extracts. This may indicate that clinical status is the better way to evaluate the surfactant replacement therapy.

The lungs from premature humans dying from the respiratory distress syndrome (RDS) have abnormal surface active properties (5) and decreased amounts of surfactant (1, 6.7). A treatment for RDS might be the administration of surfactant through the airway. Our studies using surfactant-depleted adult rat lungs show that nebulization with either synthetic dipalmitoyl phosphatidylcholine or natural surfactant does not restore pressure-volume (P-V) characteristics. However, the direct instillation of natural surfactant restores the lung P-V characteristics to normal (11). Although saturated phosphatidylcholine (SPC) alone or in combination with other phospholipids administered by direct instillation restores the P-V characteristics of the surfactant-depleted lung toward normal. none is as effective as natural surfactant (12).

Our clinical, morphologic, and physiologic findings using a premature twin lamb model at 120 days gestational age demonstrate that the administration at birth of natural surfactant to premature lambs via the trachea protects the animals from developing many early features of RDS for a period of $2 \mathrm{hr}(3)$. In a previous study, equivalent amounts of surfactant to that recovered by lavage from a $2-$ to 3 -day-old lamb was instilled $(173 \mathrm{mg}$ total lipid per $\mathrm{kg}$ ). Assuming that all the surfactant instilled into the trachea reaches the alveoli. this amount should be more than necessary to prevent respiratory failures in 120-day premature lambs. This study is designed to define the minimal amount of natural surfactant needed to prevent RDS in premature lambs.

\section{MATERIALS AND METHODS}

The protocol for this study was identical to that used before (3). In summary, 10 pairs of twin premature lambs between 118 and 120 days gestation were delivered by caesarean section. Amniotic fluid and tracheal fluid samples were used for the shake test (9) for pulmonary maturity. Arterial blood from the ewe and umbilical vein blood from the lambs were used for $\mathrm{pH}, \mathrm{pO}_{2}$, and $\mathrm{pCO}_{2}$ measurements. The fetal trachea was tracheostomized before delivery of the entire fetus, and based upon the estimated body weight (BW), the treated lambs received different amounts of natural surfactant suspended in $15 \mathrm{ml}$ of distilled water. The natural surfactant was instilled directly into the tracheal cannula before the first breath. The control lamb received no treatment. Each lamb was then ventilated by hand once with $100 \%$ oxygen and then ventilated with room air using a small animal volume respirator. The initial respirator settings were a rate of $60 / \mathrm{min}$, a tidal volume of $5 \mathrm{ml} / \mathrm{kg}$ (estimated $\mathrm{BW}$ ), a positive end expiratory pressure of $4 \mathrm{~cm} 1 \mathrm{I}_{2} \mathrm{O}$. and inspiration to total cycle ratio of 0.4 An umbilical artery catheter was placed for continuous recording of blood pressure and heart rate, and blood gases and $\mathrm{pH}$ were measured at least every $30 \mathrm{~min}$. No bicarbonate, oxygen, or transfusion therapy was used. The body temperature of each lamb was monitored with a rectal thermometer and was maintained in the range of 38 to $39^{\circ} \mathrm{C}$ by adjusting overhead heat lamp and a (Gaymar) heating blanket. After $2 \mathrm{hr}$ of ventilation, the surviving lambs were sacrificed by a cisternal injection of xylocaine.

The natural surfactant was prepared as before (12) using lavage from 2- to 3-day-old lamb lungs. Lipids were extracted from an aliquot of the natural surfactant with $\left(\mathrm{HCl}_{3}: \mathrm{MeOH}(2: 1 \mathrm{v} / \mathrm{v})\right.$ and washed (10). The total lipids were determined gravimetrically using a Cahn M-10 electrobalance. The phospholipid composition of the surfactant was in agreement with our previous study (3). To determine the purity of our isolated natural surfactant, the surface tension was measured on 5 representative preparation from 8 newborn lambs using a Wilhelmy balance. The maximun trough was $64 \mathrm{~cm}^{2}$ which upon compression was reduced to 12.8 $\mathrm{cm}^{2}$. Cycling times of 3 min were used. The amount of natura surfactant applied to the surface was 2.0 to $4.0 \mu \mathrm{g} / \mu \mathrm{l}$ of lipid.

Measurements of surface tension of saline extracts of mincer lung with a Wilhelmy balance, the P-V characteristics of the lungs and water content of lung were as before (3). From the minima $(\gamma \min )$ and maximal surface tension $(\gamma \max )$ the stability indice were then calculated according to the formula:

$$
\text { Stability index }=\frac{2(\gamma \max -\gamma \min )}{\gamma \max +\gamma \min }
$$


All values are expressed as mean \pm S.E. Statistical significance was calculated using the test (Student distribution).

\section{RESULTS}

\section{AMOUNT OF NATURAL SURFACTANT INSTIILEI)}

Because the natural surfactant was instilled based on the estimated body weight of the fetus, there was a small variation in the actual amount of surfactant administered per $\mathrm{kg}$ body weight (Table 1). The four groups of lambs received: no surfactant; 19 $\pm 0.5 \mathrm{mg}$ surfactant total lipid (TL) per $\mathrm{kg}: 53 \pm 2.1 \mathrm{TL}$ per $\mathrm{kg}$; and $64 \pm 1.6 \mathrm{mg} T L$ per $\mathrm{kg}$. The data for the dose of $173 \pm 12.6$ $\mathrm{mg}$ surfactant TL per $\mathrm{kg}$ are from the previous study (3).

\section{(IINICAI. PARAMITIERS}

All the lambs had soft hoofs, sparse hair, and fused eyelids, and were active at birth. The shake test (9) on amniotic fluid and tracheal fluid samples for all the lambs was negative. The blood gases and $\mathrm{pH}$ of umbilical vein blood of the fetus (Figs. I to 3) and arterial blood from the ewe were normal. The blood pressure of all the lambs was $62 \pm 2.4 \mathrm{~mm} \mathrm{Hg}$ shortly after delivery.

The lambs receiving no surfactant died within $40.1 \pm 7.5 \mathrm{~min}$ of birth, whereas the lambs treated with natural surfactant survived the 2 -hr experimental period. The peak inspiratory pressure at $2 \mathrm{hr}$ of the surfactant-treated lambs was the same for groups B. C. D. and $\mathrm{E}$ and was $21.4 \pm 0.1 \mathrm{~mm} \mathrm{Hg}$. This pressure was significantly lower $(P<0.001)$ than for the untreated group $\mathrm{A}$ $(30.7 \pm 1.4 \mathrm{~mm} \mathrm{Hg})$ at the time of death. There were also no

Table I. Amount of natural surfactant instilled

\begin{tabular}{|c|c|c|c|c|c|}
\hline (iroup & $\begin{array}{l}\text { No. of } \\
\text { lambs }\end{array}$ & Wt (kg) & $\begin{array}{l}\text { Amount of sur- } \\
\text { factant instilled } \\
{[T L(\mathrm{mg} / \mathrm{kg})]}\end{array}$ & $\begin{array}{l}\text { "i sur- } \\
\text { vived }\end{array}$ & $\begin{array}{l}\text { Lung } \\
\left.\mathrm{HO}()^{\prime}\right)\end{array}$ \\
\hline$A$ & 7 & $2.1 \pm 0.2^{1}$ & 0 & () & $88 \pm 0.8$ \\
\hline B & 4 & $2.2 \pm 0.1$ & $19 \pm 0.5$ & 100 & $88 \pm 0.9$ \\
\hline c & 5 & $2.4 \pm 0$ & $53 \pm 2.1$ & 100 & $89 \pm 0.3$ \\
\hline D & 4 & $2.3 \pm 0.2$ & $64 \pm 1.6$ & $1(0)$ & $88 \pm 0.5$ \\
\hline$E^{2}$ & 10 & $1.6 \pm 0.1$ & $173 \pm 12.6$ & 100 & $88 \pm 0.4$ \\
\hline
\end{tabular}

'Mean \pm S.E.

Data from Ref. 3.

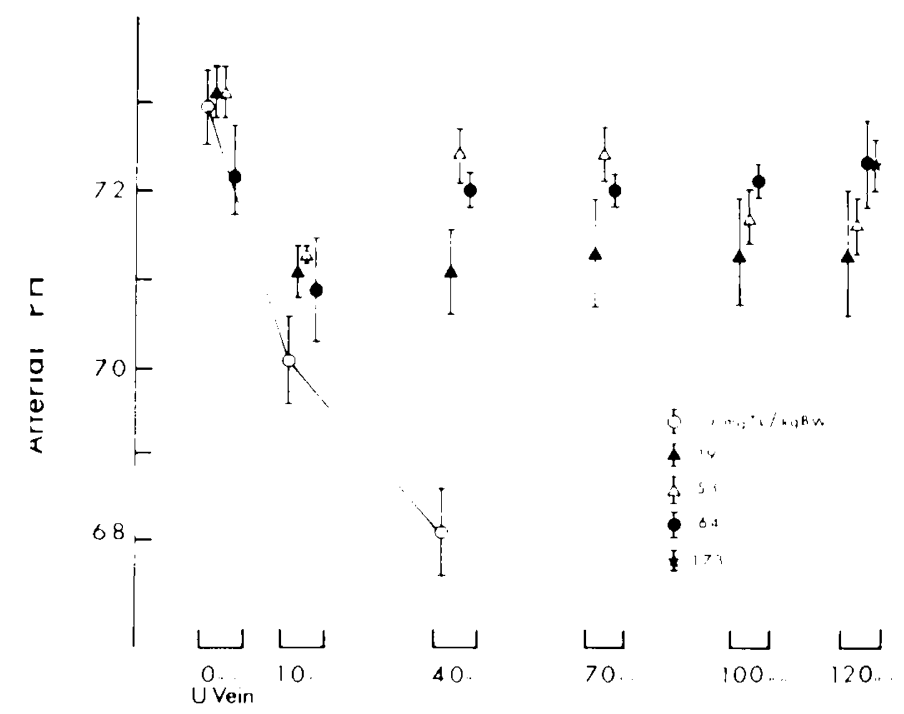

Fig. I. Arterial pll changes. Blood samples were taken from the umilical vein ( $U$ vein) hefore delivery and from umbilical artery catheters dvanced to the abdominal aorta at least every $30 \mathrm{~min}$. ('hanges in arterial IH of lambs receiving different amounts of surfactant Tl. per $\mathrm{kg}$ before he first breath are shown.

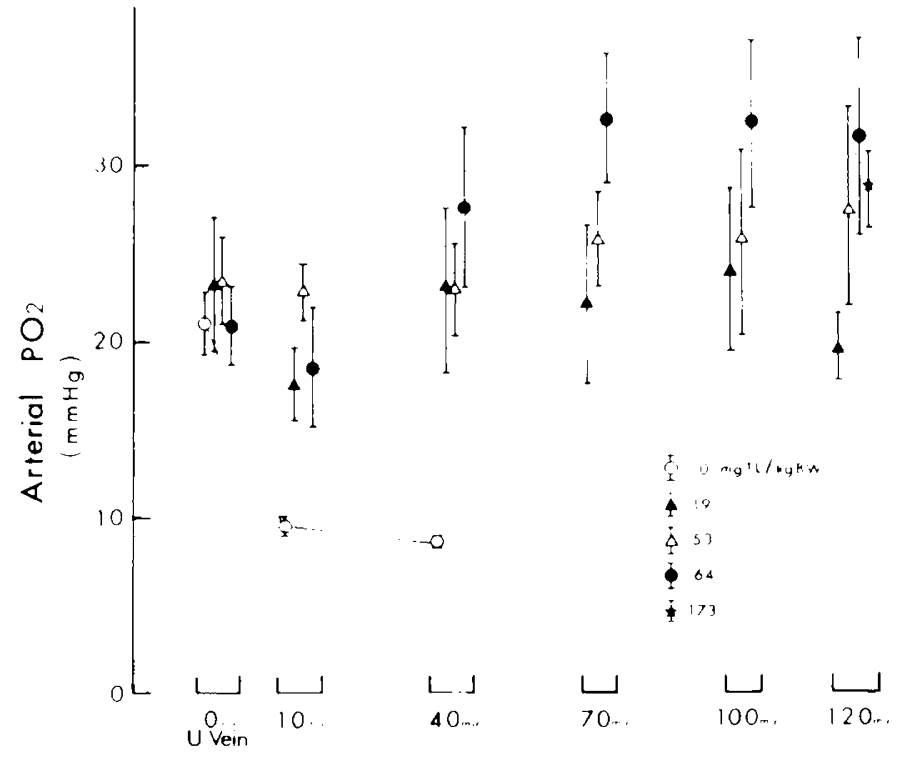

1:ig. 2. Arterial pO, changes. (hanges in arterial po, for a period of 2 hr are shown for lambs receiving different amounts of natural surfactant and ventilated with room air

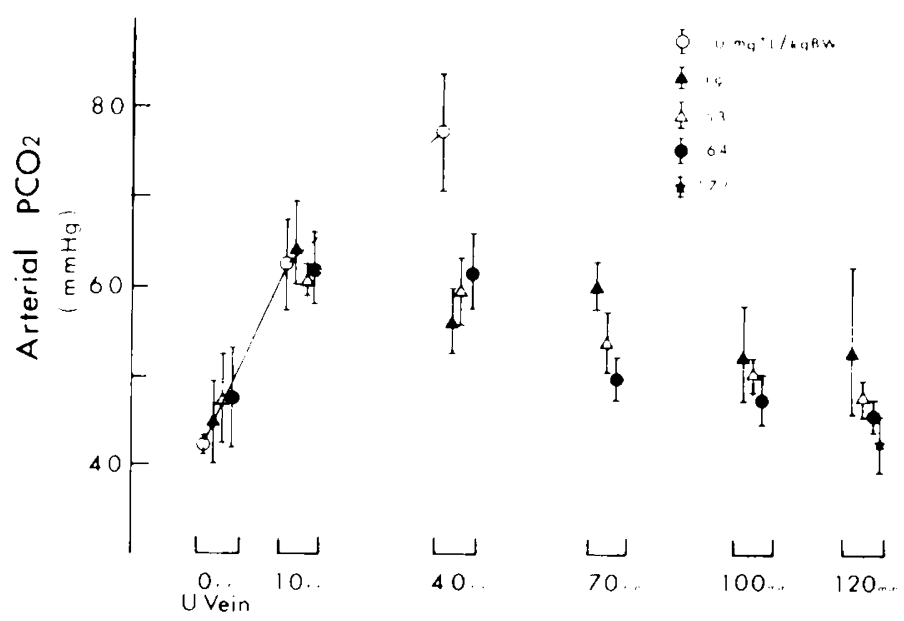

1.ig. 3. Arterial p( $\mathrm{O}$. changes. (hanges in arterial $\mathrm{pCO}$. for a period of $2 \mathrm{hr}$ are shown for lambs receiving different amounts of natural surfactant.

differences between the groups B. C and D in the spontaneous movement, responses to pain. and urine output.

The arterial $\mathrm{pH} . \mathrm{pO}_{2}$ and $\mathrm{pCO}$. values are given in Figures 1 , 2 and 3 . The untreated lambs died with severe acidosis, hypercarbia, and hypoxemia, the values before death were $\mathrm{pO}, 9 \pm 0.4$ $\mathrm{mm} \mathrm{Hg}$ : p $\mathrm{O} .0 .77 \pm 7 \mathrm{~mm} \mathrm{Hg}$ : and pH. $0.83 \pm 0.05$. In contrast. the blood gas values for the treated lambs (groups B. C, and D) were similar to those measured for lambs receiving $173 \mathrm{mg} T L$ per $\mathrm{kg}$ surfactant, and the blood gas values seemed to improve with time. There were no statistical differences in blood gas values between the animals receiving different amounts of surfactant $(P$ $>0.05)$.

I.UNG W WATHE CONTENT

There were no differences in lung water content between groups. The control group which here received nothing had the same water content as the control groups in our previous study receiving either $15 \mathrm{ml}$ of saline or distilled water (3) 


\section{P.V CHARACTERISTICS OF LIUNG;}

The P-V characteristics of the left lungs from each group were expressed as the $\mathrm{ml}$ of air per $\mathrm{g}$ lung weight at $7 \mathrm{~cm} \mathrm{H}_{2} \mathrm{O}$ on the deflation limb of the P-V curve (Fig. 4). Although the lungs from lambs receiving $19 \mathrm{mg} \mathrm{TL}$ per $\mathrm{kg}$ had retained more air than untreated lambs $(P<0.001)$, less volume was retained than for lungs from lambs treated with greater than $53 \mathrm{mg} \mathrm{TL}$ per $\mathrm{kg}$ surfactant $(P<0.05)$. The P-V characteristics of the groups receiving 53 and $64 \mathrm{mg}$ TL per $\mathrm{kg}$ surfactant were similar to those of lambs treated with $173 \mathrm{mg}$ TL per $\mathrm{kg}$ surfactant.

\section{SURFACE TENSION (FIC; 5)}

Minced lung tissue from control animals showed extremely high minimal surface tension, indicating lung immaturity and abnormal surface active properties. Instillation of $19 \mathrm{mg}$ TL per $\mathrm{kg}$ surfactant lowered the surface tension of the lung extracts to $26 \pm 1.3$ dynes/ $\mathrm{cm}$, a value higher than that measured for normal lung. The surface tension was lowered to under 10 dynes/cm with the dose of $64 \mathrm{mg}$ TL per mg surfactant, a surface tension as low as that

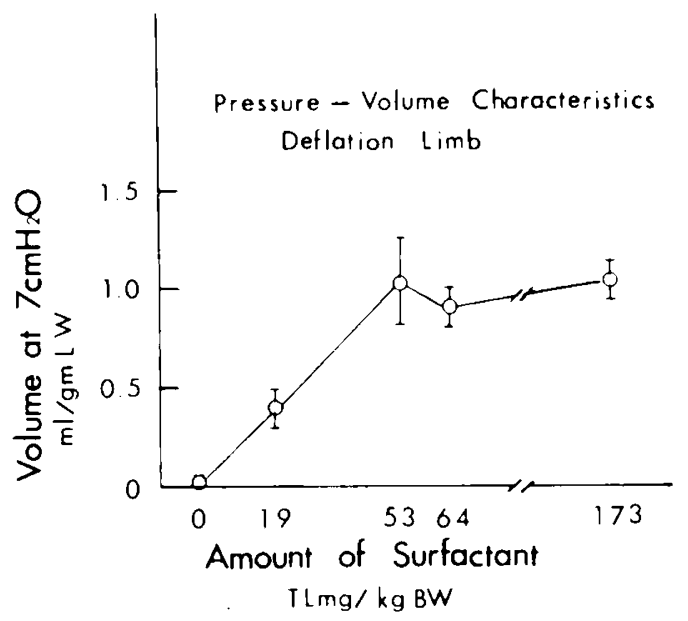

Fig. 4. P.V characteristics of lamb lungs. The volume $(\mathrm{ml} / \mathrm{g}$ lung weight) at $7 \mathrm{~cm} \mathrm{H} \mathrm{O}$ on the deflation limb of $\mathrm{P}-\mathrm{V}$ curve are shown versus the amount of natural surfactant the lambs received.

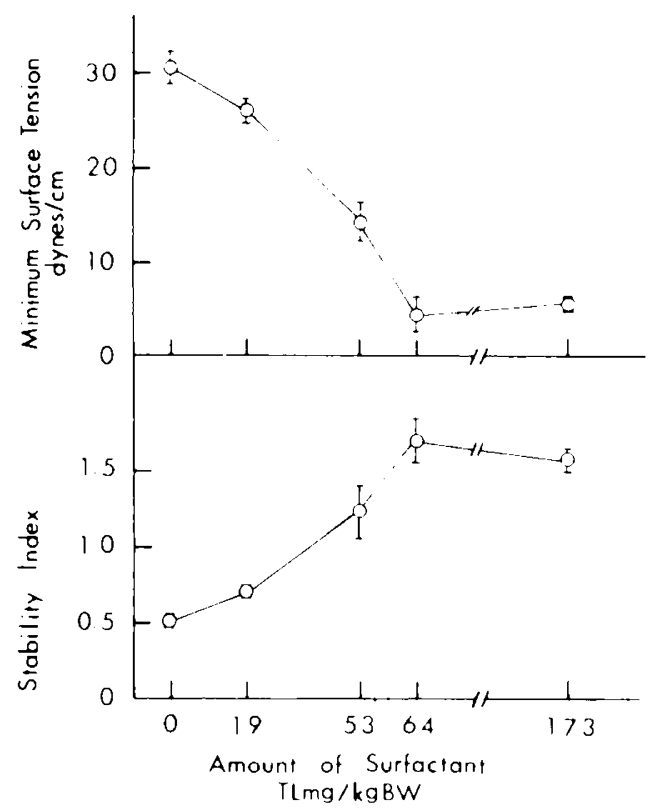

Fig. 5. Minimum surface tension of minced lung fluid and calculated stability index. Surface tension measurements were made on saline extracts of the lungs of lambs receiving different amounts of surfactant. measured for lambs receiving $173 \mathrm{mg}$ TL per $\mathrm{kg}$ surfactant. As a way of expressing the stabilizing ability of the surface film. the stability index was calculated $(8)$. The stability index was as high as that measured for the normal lung $(>1.0)$ when the lambs received $53 \mathrm{mg}$ TL per $\mathrm{kg}$ surfactant or more.

\section{SLRFAC TENSION STUIDISS OF THIE NATURAL SUREACTANT}

The mean value of surface concentrations of our natural surfactant that lowered the minimum surface tension to 11 dynes $/ \mathrm{cm}$ was $0.62 \pm 0.04 \mu \mathrm{g} / \mathrm{cm}^{2} \mathrm{SPC}$. Our material further reduced the minimum surface tension to 0 dynes/cm at the concentration of $0.76 \pm 0.03 \mu \mathrm{g} / \mathrm{cm}^{2}$ SPC. The values reported by $\mathrm{King}$ and Clements (13) for purified surfactant from dog lung was $0.35 \mu \mathrm{g}$ $S P C$ per $\mathrm{cm}^{2}$ reduced the surface tension to 12 dynes $/ \mathrm{cm}$.

\section{DISC USSION}

The marked lowering of surface tension by surface-active material is a mass-related property resulting from the orientation of surfactant molecules into a close-ordered array at the air-fluid interface. In this study, the dose-related effects were seen between the amount of surfactant instilled and the clinical status and surface activity measurement.

The material referred to as the natural surfactant in this study meets the established criteria for the pulmonary surfactant and had surface active properties similar to the purified surfactant (13). King and Clements (13) suggest that the theoretical amount of pulmonary surfactant required to cover the alveolar surface with a duplex film is at least $1 \mathrm{mg} / \mathrm{g}$ lung. which is $0.88 \mathrm{mg} \mathrm{TL}$ per g lung ( $T L=88 \%$ of surfactant). The mean wet lung weight of 40 premature lambs in this and our previous study is $82.8 \mathrm{~g}$. and the mean body weight is $2.0 \mathrm{~kg}$. Therefore. the theoretical amount of surfactant required to cover the alveolar space of these premature lambs should be about $36.4 \mathrm{mg}$ TL per $\mathrm{kg} \mathrm{BW}$ purified surfactant. providing that all of the surfactant instilled into the trachea reaches the alveoli. This estimate is somewhat higher than the $20 \mathrm{mg} / \mathrm{kg}$ recovered from the lungs of 6 -hr-old normally breathing lambs (2) and adult rats (14). This theoretical amount is similar to the amount of surfactant which showed the good surface activity when instilled into lambs in this study.

There were intriguing differences between doses needed to normalize in vivo versus in vitro measurements. The effects of a 64 $\mathrm{mg} T \mathrm{~T}$ per $\mathrm{kg}$ dose were similar to those following a dose of 173 $\mathrm{mg}$ TL per kg using surface activity criteria. The $19 \mathrm{mg}$ dose of surfactant showed significant improvement in P-V measurements and surface tension measurements compared with results from control animals, but had much less surface activity than measured for lambs receiving $53 \mathrm{mg} \mathrm{Tl}$ per $\mathrm{kg} \mathrm{BW}$ or more surfactant. However, $19 \mathrm{mg}$ TL per $\mathrm{kg} \mathrm{BW}$ was sufficient to preserve lung function; the $\mathrm{pH}$ and blood gas measurements and survival were similar to those measured for lambs receiving $53 \mathrm{mg}$ TL per $\mathrm{kg}$ BW or more surfactant. Thus measurements of clinical status probably are better than surface activity measurements for the assessment of adequate dosage for the treatment of RDS.

There were no differences in the data between the untreated control lambs in this study and control lambs in our previous study who received intratracheal saline or distilled water. All the lungs had the same percentage of water as in the fetal state (2), no matter what treatment and diluent was used. Inasmuch as fetal lung fluid disappears slowly (4), the instillation of $15 \mathrm{ml}$ of fluid before first breath would not make any difference in lung water content.

Although our previous studies and this work show that surfac. tant deficiency-mediated respiratory failure can be prevented ir premature lambs by the endotracheal instillation of natural surfactant. several questions need to be answered before considering surfactant replacement as a therapy for RIDS in the prematurt human. This study indicated how much material may be needed but methods and timing of administration and duration of effec must be defined in experimental animals. 


\section{REFERENCES AND NOTES}

I. Adams, F. H., Fujiwara, T., Emmanouilides, $C_{\text {i. }}$ C.. and Scudder. A.: Surface properties and lipids from lungs of infants with hyaline membrane disease. J. Pediatr.. 60: 357 (1965)

2. Adams, F. H., Fujiwara, T.. and Latta, H.: "Alveolar" and whole lung phospholipids of premature newborn lambs. Biol. Neonate. 17: 198 (1971).

3. Adams, F. H., Towers, B., Osher, A. B., Ikegami. M., Fujıwara. T., and Nozaki. $M$.: Effects of tracheal instillation of natural surfactant in premature lambs. I. Clinical and autopsy findings. Pediatr. Res.. 12: 841 (1978).

4. Adams, F. H.. Yanagisawa, M.. Kuzela. D., and Martinek, H.: The disappearance of fetal lung fluid following birth. J. Pediatr., 78 : 837 (1971).

5. Avery, M. E.. and Mead. J.: Surface properties in relation to atelectasis and hyaline membrane disease. Am. J. Dis. Child.. 97: 517 (1959)

6. Brumley, (;. W. Hodson. W. A.. and Avery. M. E.: L.ung phospholipids and surface tension correlations. Pediatrics, 40): $13(1967)$

7. Chu, J., Clements, J., Cotton, E., Klaus, M., Sweet. A.. Thomas, M., and Tooley. W.: The hypoperfusion syndrome. Pediatrics, 35: 733 (1965).

8. Clements. J. A.: Surface tension in the lung. Sci. Am., 207: 120(1962)

9. (lements, J. A.. Platzker, A. (.. Tierney. D). F.. Hobel. (C. J.. Creasy, R. K., Margolis, A. J.. Thiebault. D. W.. Tooley, W. H.. and Oh. W.: Assessment of the risk of respiratory distress syndrome by a rapid test for surfactant in amnsotic tluid. N. Engl. J. Med., 286: 1077 (1972)

10. Folch, J., Lees, M., and Sloane-Stanley, G. H.: A simple method for the isolation and purification of total lipids from animal tissue. J. Biol. Chem., 220: 497 (1959).

II. Ikegami, M., Hesterberg. T.. Nozaki. M., and Adams, F. H.: Restoration of lung pressure-volume characteristics with surfactant: comparison of nebulization versus instillation and natural versus synthetic surfactant. Pediatr. Res.. 11: 178 (1977).

12. Ikegami. M. Silverman. J., and Adams, F. H.: Restoration of lung pressurevolume characteristics with various phospholipids. Pediatr. Res, 13:777 (1979)

13. King, R. J., and Clements. J. A.: Surface-active materials from dog lung. II Composition and physiological correlations. Am. J. Physiol., 223: 715 (1972).

14. Young, S. L., and Tierney, D. F.: Dipaimitoyl lecithin secretion and metabolism by the rat lung. Am. J. Physiol., 226: 539 (1972).

15. The authors thank Dr. Alan Jobe for reviewing the manuscript

16. Requests for reprints should be addressed to: Machiko Ikegami. M.D., FetaiMaternal Research Laboratories, Building A-17, Harbor-UCLA Medical Center, I000 West Carson Street. Torrance. CA 90509 (USA).

17. This research was supported by funds from the USPHS and the National Cystic Fibrosis Research Foundation.

18. Received for publication July 16, 1979

19. Accepted for publication January 9, 1980 